\title{
ELECTRONIC COMPUTATION AND BOOK-KEEPING IN IGNEOUS PETROLOGY
}

by

Felix Chayes

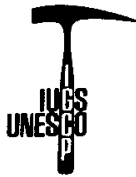

Designed to assist in the construction of a world data base for igneous petrology, IGCP Project 163 and its success depend upon the level of interest and support it receives from the petrological community. This article ${ }^{\star}$ illustrates with practical examples the need for a publicly accessible, comprehensive electronic data base if scholarly standards are to be maintained and "epidemics" of further specialization avoided.

\section{Introduction}

An ambitious attempt to computerize a large part of the published corpus of igneous petrology is now in progress. The new data base being developed by IGCP Project 163, with the support and encouragement of the IUGS Committee on Storage, Automatic Processing and Retrieval of Geological Data (COGEODATA), is to include data for igneous rocks of all kinds and ages. For those rocks with a reasonably "complete" essential-oxide analysis published since 1918, the base will include not only that analysis but also published information about the petrography, mineral assemblage, geological association, age, and trace element content of the analyzed specimen. Source references from which these different types of information have been drawn will be separately indexed and cited in the base. An associated information system will provide highly selective retrievals and reductions for any interested petrologist.

One might question whether the availability of such a facility will be of sufficient scientific advantage to warrant the time and effort expended toward its development. Petrologically inclined readers may be persuaded of this by some examples of novel, useful, and otherwise unobtainable results extracted in routine fashion from a much more primitive base, that is, one sharply restricted both in coverage and information content.

The work described here has utilized only program elements of my own information system, which scans a data base consisting solely of published analyses of Cenozoic volcanic

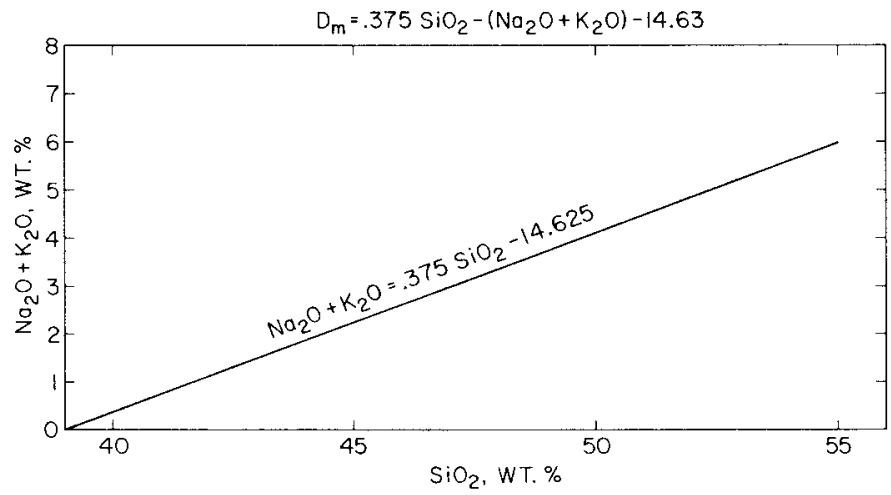

Figure 1. The Macdonald-Katsura basalt classification, (Macdonald and Katsura, 1964). rocks, together with the source names of the analyzed specimens. Most of it would have been either impossible or immensely impractical in the absence of some such system. All of it could be done much better, and some of it should be redone, with a base of the sort under development by IGCP Project 163.

\section{Distinguishing Alkaline from Other Basalts}

The well known Macdonald-Katsura partition of Hawaiian basalts was suggested in 1964 and is basically graphical. Stated numerically, it involves evaluation of $\underline{D}_{m}=0.37 \mathrm{SiO}_{2}$ $\left(\mathrm{Na}_{2} \mathrm{O}+\mathrm{K}_{2} \mathrm{O}\right)-14.63$ and the classification rule that a basalt is to be considered alkaline if and only if $\underline{D}_{m}<0$, for only then will its analysis plot above the diagonal line in Figure 1. Two years later I proposed an alternative discriminant that partitions the space of the Tilley-Muir projection, namely $\underline{D}_{C}$ $=$ hy $^{\prime}+0.1301^{\prime}-26.49$, with the classification rule that $\bar{a}$ basalt is to be considered alkaline if and only if $\underline{D}_{C}<0$, for only then will its analysis plot to the left of the line shown in the central ternary of Figure 2. The first discriminant depends entirely and directly on silica and alkali content. The second discriminant considers silica only indirectly and alkalis not at all. How do the two compare?

For the 627 Hawaiian analyses available in the base when a test at last became practical (Chayes, 1975a), there is, as

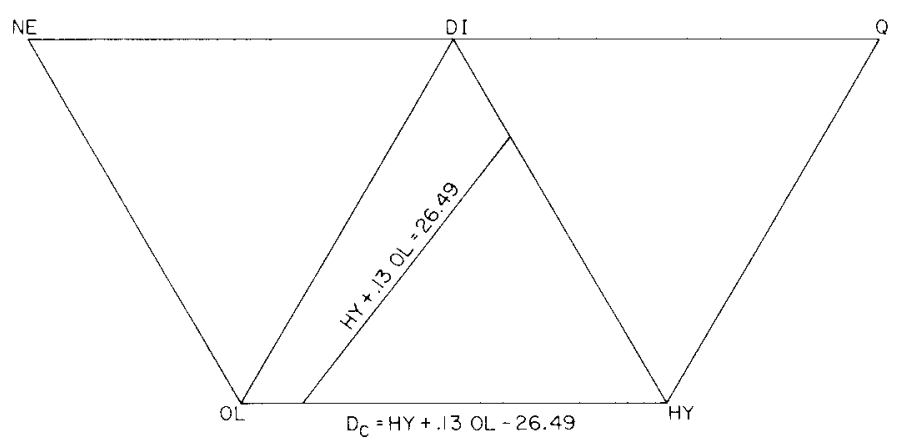

Figure 2. Classification of basalt by partition of the space of the Tilley-Muir projection.

* This article has been adapted from a paper delivered at the GSA Annual Meeting in Toronto on October 23 , 1978, entitled "Applications of Petrological Information Systems to Geological Problems". 
shown in Table 1 , a probability of about $7 / 8$ that $\underline{D}_{m}$ and $\underline{D} \mathrm{c}$ will classify an analysis similarly. Differences between the discriminants are perhaps of even more substantive interest than the gratifyingly high level of their agreement. But the interpretation and respective merits of the two schemes are not at issue here. What is at issue is that comparisons of this kind, impractical if computation is to be by hand, are scarcely more than minor exercises if the data are included in the base of an information system capable of evaluating, storing, and using simple linear combinations of system variables. In this particular example, the comparison is between considerably less than a minute of machine time and, I would estimate, considerably more than a month of uninterrupted 8-hour days spent at a desk calculator.

\section{Table 1}

Partition of 627 Analyses of Hawaiian Lavas by Means of the ol'-hy' Linear Discriminant $\left(\underline{D}_{C}\right)$ and the Numerical Equivalent of the

Macdonald-Katsura Procedure $\left(\underline{D}_{m}\right)^{*}$

$\begin{array}{lccc} & \underline{\underline{D}}_{\underline{C}}>0 & \underline{D}_{C}<0 & \text { Totals } \\ \underline{D}_{m}>0 & 400 & 42 & 442 \\ \underline{D}_{m}<0 & 39 & 146 & 185 \\ \text { Totals } & 439 & 188 & 627\end{array}$

*From Chayes (1975a). Note the $(400+146) / 627$ or $87.1 \%$ of the specimens are classified similarly by $\underline{D}_{C}$ and $\underline{D}_{m}$.

\section{Average Composition of Rocks}

The calculation of average compositions for various rock types is such an obvious and common application of petrographic information systems that it requires only brief discussion. Interested readers will find a set of such systemgenerated average compositions, for the commoner Cenozoic volcanic rocks, in Table 35 of Chayes (1975b). Again, a vast amount of hand labor (fraught with opportunity for clerical error and almost impossible to check except by redoing) is replaced by astonishingly small amounts of machine time.

Among the critical advantages of the electronic information system approach to this work is the fact that alternative selection and partition procedures may be applied at negligible additional cost. Instead of a single world-average or a few regional averages for the composition of a particular rock type, one may almost as easily generate and compare averages found for it under a wide variety of independent or interdependent geographic, tectonic, geological, stratigraphic, and mineralogical constraints. The only practical limits to the use of such selective scanning specifications are the coverage and information content of the data base attached to the information system.

\section{On Revision of Rock Nomenclature and Classification}

Most current suggestions in this area contemplate replacement of mineralogical criteria by chemical ones. With a data base containing the names and essential element composi- tions of analyzed specimens, it is possible to examine in detail two matters about which inadequate information is largely responsible for both the introduction of new classificatory devices of this type and ultimately, for their replacement. Specifically, by means of discriminant function analysis, one may determine

(a) the chemical consistency of existing usage, and

(b) the maximum level of discrimination that could be achieved by any set of chemical criteria based on these variables.

With the essential oxides as variables and the source names establishing the "a priori classification" (in this case, simply the existing usage) an initial random sampling of the reservoir of analyses in the base serves as input to a program that provides estimates of the coefficients of the two-group discriminant function for any pair of names, and then uses the function as a classificatory device in a second sampling. The consistency of the function, the quantity of interest, are defined as the proportion of specimens of any two types classified similarly by existing usage and the discriminant function. The process is repeated for each pair of names involved, leading finally, for the most common names, to the display shown in Figure 3, in which the row and column captions include all principal nouns occurring more than 250 times* in the version of the base used for this study.

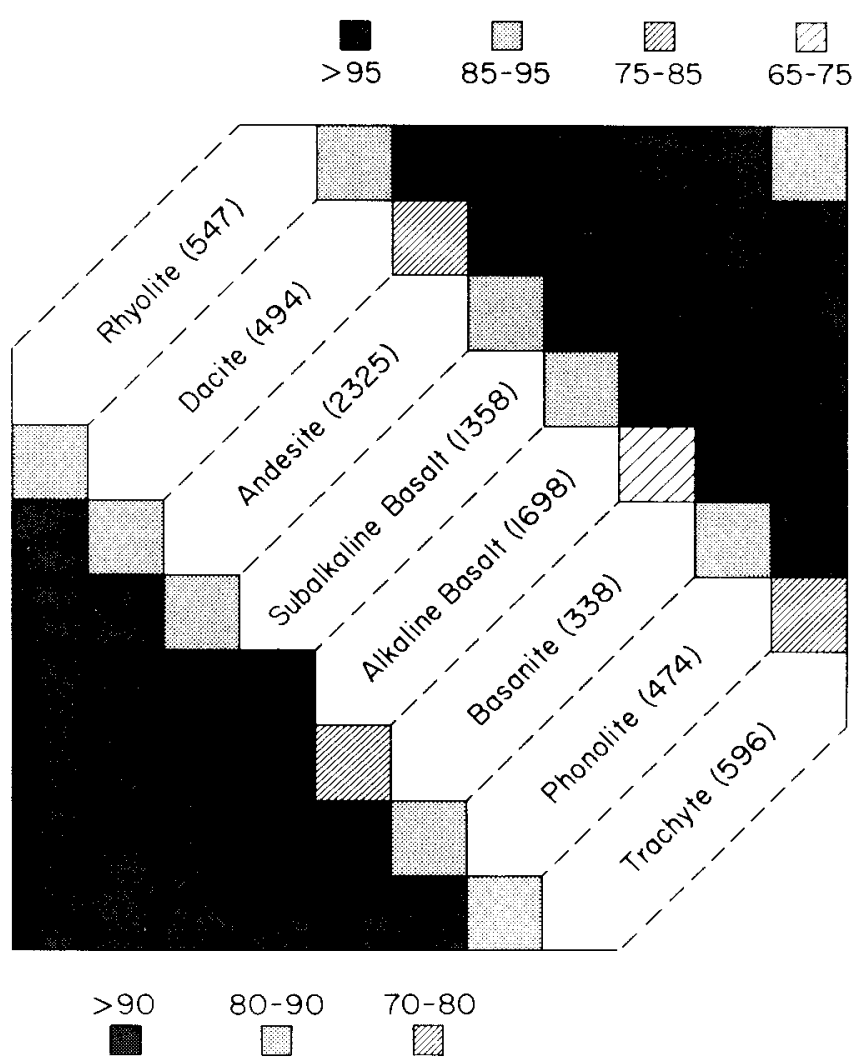

Figure 3. Consistency of classification of common Cenozoic volcanic rocks by binary discriminant functions using all essential oxides. (Both parts of diagram are based on same data. In upper right, $>95 \%$ consistency is required of an optimum discriminant; in lower left, the optimum-grade boundary is $90 \%$. Other classes in both parts cover adjacent $10 \%$ ranges.)

* Except for subdivision of the basalts, all names are as given in the source references. The basalt partition is based entirely on $\underline{D}_{C}$, as described above. Though not uncommon in generalized summaries, compositional modifiers are rarely used in names clearly attached to particular analyzed specimens of Cenozoic rocks called basalt. 
The patterning of the figure is based on the average percentage of consistent classifications in three random samples consisting of approximately equal numbers $(s 150)$ of analyses of rocks referred to by each of the indicated row and column headings (Chayes, 1977). With the more stringent definition of "optimum" used in the upper right half of the figure, every one of the eight names is involved in two lessthan-optimum binary chemical discriminants. From the figure it is clear where attempts to revise and improve nomenclature should be centered. It is both convenient and unusual to be able to display these 36 comparisons in a single diagram based on a uniform grading scheme, but the overall results are, of course, scarcely novel.

In addition to showing how consistent with current usage a classification based on bulk composition actually is, each discriminant calculated directly from the essential oxides (as all these are) maximizes the "distance" between some pair of rock types. In a least-squares sense, no other linear combination of the same variables (or of any subset of them) can be more effective in this respect. Extension of this property to what is here defined as consistency is obvious, novel, and extremely informative. It establishes that we cannot expect systematically better performance from any normative or other arbitrary recasting of the analyses, however useful for other purposes.

We might improve performance by using additional information in the classifying process. The most obvious candidates are mineral assemblage and trace element content, but of course the systematic use of either will require, as a starting point, a base of just the type that IGCP Project 163 is attempting to create.

Frequency Distributions of Some of the Essential Elements in Cenozoic Volcanic Rocks

Characterization and comparison of the frequency distributions of the major rock-forming elements are better studied with an electronic information system. Five examples drawn to a common scale are shown in Figure 4.

The mean values posted in this Figure confirm Goldschmidt's (1928) well known dictum that the lithosphere is essentially an oxysphere. In the part of it consisting of Cenozoic volcanic rocks, as may be seen from sample statistics assembled elsewhere (Chayes, 1976a, b, Table 62), more than $45 \%$ by weight (nearly $62 \%$ by number) of all atoms are oxygen. The next most abundant atom, $25 \%$ by weight (19\% by number), is silicon. Despite the fact that oxygen is nearly twice as abundant as silicon (by weight), the second moment of $\mathrm{Si}$ is about four times that of oxygen. Furthermore, oxygen has by far the smallest, and silicon by a very great margin the largest, third moment. Both are positive. That for oxygen is so small as to represent only a trifling departure from symmetry. The positive skew of Si, on the other hand, is little short of overpowering. It will persist even if frequencies of published analyses of rhyolitic and basaltic rocks underestimate the relative frequency of the former by a factor of 3 or 4 . The next seven cations in order of abundance fall into two groups with regard to skew-- $\mathrm{Mg}$, $\mathrm{Na}, \mathrm{K}$, and $\mathrm{Ti}$ are positively skewed; $\mathrm{Al}, \mathrm{Fe}$, and $\mathrm{Ca}$ show negative skew. I am not aware that negative skew has been noted in this context before, but as shown in the top half of Figure 4 , it is unmistakable, however unexpected.

The petrological significance of these negative skews is not at all clear. It is obvious that in completely crystalline materials, compositional maxima must be imposed by mineral composition. It is not to be expected, for instance, that any common eucrystalline igneous rock could contain more Al than anor thite, more $\mathrm{Ca}$ than diopside, or more $\mathrm{Fe}$ than, say, hypersthene, but these mineralogical limiting values are so much higher than the modal classes of $\mathrm{Fe}, \mathrm{Al}$, and $\mathrm{Ca}$ as to exert very little necessary influence on the shapes of the distributions. Evidently we are dealing with the limits and relative frequencies of magma compositions. The sharp upper truncation of Fe content is perhaps the most striking,
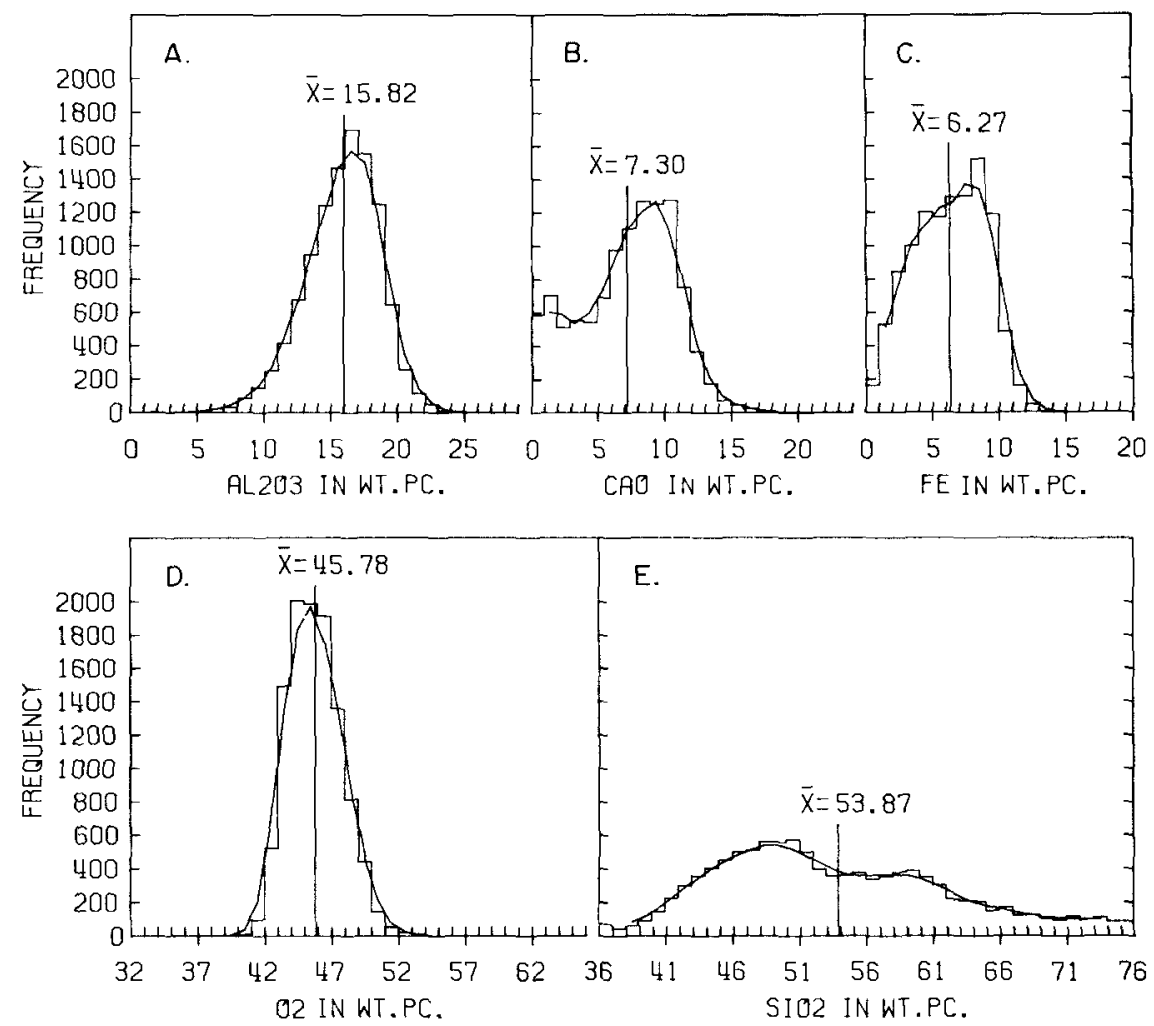

Figure 4. Frequency distributions of $\mathrm{Al}_{2} \mathrm{O}_{3}, \mathrm{CaO}, \mathrm{Fe}, \mathrm{O}_{2}$, and $\mathrm{SiO}_{2}$ in 10,869 analyses of Cenozoic volcanic rocks. 
suggesting that in this respect Fe-rich complexes like Skaergaard, for instance, are highly anomalous. Is the abrupt Fe truncation perhaps a consequence of the slagging or other process by which silicate and metallic materials were separated in the early history of the earth?

One notes that negative skews occur in the cations immediately succeeding $\mathrm{Si}$ in abundance but do not by any means compensate for the positive skew of Si. On average, the number of cations whose element distributions are positively skewed is more than twice as large as the number whose element distributions are negatively skewed, and the absolute value of the largest negative skew is much smaller than the smallest positive skew. There is thus a very considerable net excess of positive skew among cations, an excess one would imagine ought to be matched by a similar excess in the distribution of oxygen if charge balance is to be maintained. Instead, the skewness of oxygen, though positive, is virtually negligible; a slightly different choice of origin would materially reduce even the modest asymmetry of the histogram.

Is the symmetry of the oxygen distribution perhaps a consequence of the way in which the oxygen values have been extracted from the data? It is well known that sums of variables with finite variances tend to go normal (the first machine-generated random normal variates were in fact obtained by summing non-normal numbers) and the normal distribution is symmetrical. Each oxygen value used here is simply the sum $\sum_{i=1}^{\frac{n}{5}}\left(\underline{k}_{i} \underline{x}_{i}\right)$, where $\underline{x}_{i}$ is the amount and $\underline{k}_{-i}$ the $i=1$

oxygen content of the ith oxide in an analysis. The astonishingly slight asymmetry of the oxygen distribution may perhaps have resulted from this summation even though the variables summed are not independent. Because of the charge-balance requirement, one may hazard the guess that the distribution of direct oxygen determinations in the same specimens would probably show a very strong positive skew. Unfortunately, it will be many years, if not decades, before direct oxygen determinations for a broad spectrum of Cenozoic volcanic rocks will be available in sufficient number to provide a persuasive test.

On the whole, and despite the interest that such knowledge would attract, very little is known about the frequency distributions of the major components of the lithosphere. The subject obviously provides an excellent opportunity to point out, once again, the advantages of a readily accessible electronic petrographic information system. Without it, one has little more than unsupported speculation about the frequency distributions of the elements in the lithosphere.

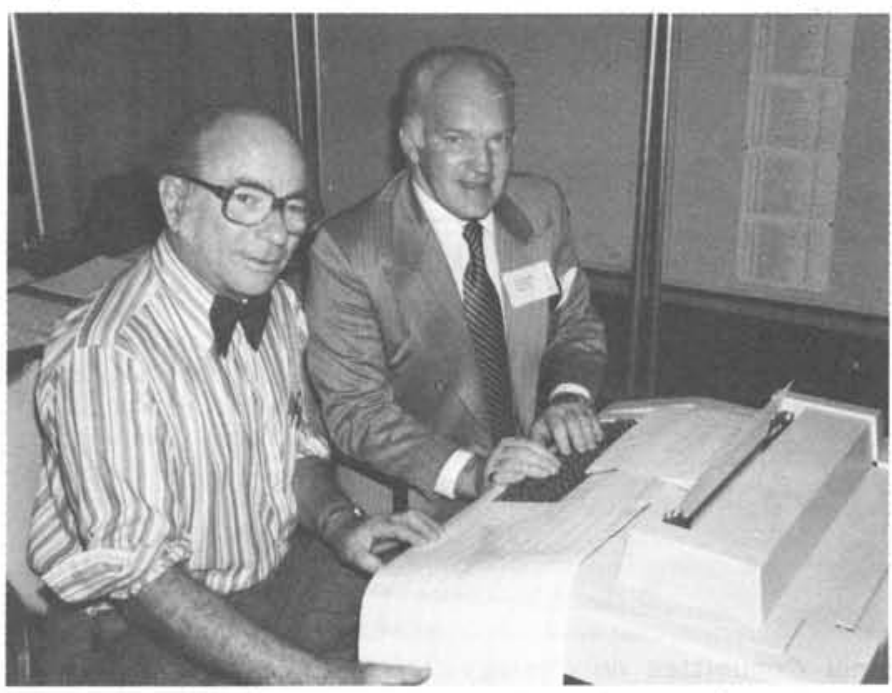

Felix Chayes (left) with Leopold Gélinas (Canada) retrieve information from a computer terminal.
With current resources it is possible to begin posing and examining some rather specific questions bearing on this subject. With a base characterized by the coverage and information content of that proposed by IGCP Project 163, it might even be possible to find answers to some of these questions.

\section{References}

Chayes, Felix, 1966, Alkaline and subalkaline basalts: Am. J. Sci., v. 264, p. 128-145.

- 1975a, On distinguishing alkaline from other basalts: Carnegie Institution of Washington Year Book, 74 , p. $546-547$.

- 1975b, Average compositions of the commoner Cenozoic volcanic rocks: Carnegie Institution of Washington Year Book, 74, p. 547-549.

- 1976a, Asymmetry in the distributions of $\mathrm{SiO}_{2}, \mathrm{Al}_{2} \mathrm{O}_{3}$, $\mathrm{CaO}$, and $\mathrm{Fe}$ in the products of Cenozoic volcanism: Carnegie Institution of Washington Year Book, 75, p. 780-781.

- 1976b, Distribution of oxygen in Cenozoic volcanic rocks: Carnegie Institution of Washington Year Book, 75, p. 781-782.

- 1977, A measure of consistency in the nomenclature and classification of volcanic rocks: Carnegie Institution of Washington Year Book, 76, p. 637-638.

Goldschmidt, V.M., 1928, Öber die Raumerfüllung der Atomen (Ionen) in Kristallen und über das Wesen der Lithosphäre: Neues Jahrb. Geol. Palaeontol., Abh., Abt. A, v. 57, p. $1119-1130$

Macdonald, G.A., and T. Katsura, 1964, Chemical composition of Hawaiian lavas: J. Petrol., v. 5, p. 82 133.

\section{Postscript:}

"Natural science is occupied very largely with prevention of waste of the labour of thought and muscle when we want to call up, for some purpose or other, certain facts of experience."

\section{P.E.B. Jourdain, in The Nature of Mathematics, quoted from J.R. Newman, The World of Mathematics.}

What Jourdain was discussing was the process of abstraction, which, in a sense, makes factual recall unnecessary, whereas what we are trying to do is replace human by electronic recall in a field where the possibility of abstraction is very limited and recall, extensive and detailed, is absolutely indispensable if we are to make any use of experience. Curiously enough, the same sentence summarizes so neatly the purpose of two such apparently diverse activities!

F.C.

ABOUT THE AUTHOR: Petrologist at the Geophysical Laboratory, Carnegie Institution (U.S.A.) since 1947, Felix Chayes was President of the Mineralogical Society of America in 1967 and currently serves on the editorial boards of that Society, the Geological Society of America, the Journal of Geology, and Chemical Geology. Project Leader of IGCP Project 163 ("Design and generation of world data base for igneous petrology"), Dr. Chayes' principal research interests are in statistical petrology and the petrography of igneous rocks. 